\title{
Sistem Pemantau Densitas Debu Gudang Elektronik: Perancangan dan Analisanya
}

\section{Electronic Warehouse Dust Density Monitoring System: Design and Analysis}

\author{
Adelia Kencana Putri ${ }^{1}$, Anantia Prakasa ${ }^{2}, *$, Mas Aly Afandi ${ }^{3}$ \\ ${ }^{1,2,3}$ Program Studi S1 Teknik Telekomunikasi, Fakultas Teknik Telekomunikasi dan Elektro, \\ Institut Teknologi Telkom Purwokerto. \\ Jl. D.I. Panjaitan No. 128 Purwokerto, Indonesia \\ 2,*Penulis korespondensi: anantia@ittelkom-pwt.ac.id \\ 117101002@ittelkom-pwt.ac.id, ${ }^{3}$ aly@ittelkom-pwt.ac.id
}

Received on 01-09-2021, accepted on 06-12-2021, published on 23-12-2021

\begin{abstract}
Abstrak
Pemantauan kualitas udara dalam gudang elektronik sangat penting untuk menjaga kesehatan manusia dan kualitas barang elektronik. Penelitian ini bertujuan untuk memantau nilai densitas debu pada suatu ruangan khususnya pada gudang elektronik, dan mengetahui hubungan antara densitas debu, suhu, dan kelembaban. Metode yang digunakan dalam penelitian ini adalah eksperimen dan uji statistik. Dan untuk uji statistik yang digunakan menghasilkan bahwa tidak ada hubungan antara densitas debu dan suhu hal ini dibuktikan dengan nilai chi-square hitung $(0,265)$ lebih kecil dari chi-square tabel $(1,645)$ dan tidak ada hubungan antara densitas debu dan kelembaban hal ini dibuktikan dengan nilai chi-square hitung $(0,1023)$ lebih kecil dari chi-square tabel $(1,645)$. Tingkat debu pada Gudang Elektronik Depo Pelita pada tanggal 22 juli 2021 sampai dengan 30 Juli 2021 memiliki rata-rata $0,13 \mathrm{mg} / \mathrm{m} 3$ atau $130 \mu \mathrm{g} / \mathrm{m} 3$. Hasil penelitian ini yaitu debu tidak dapat dipengaruhi oleh suhu dan kelembaban melainkan dipengaruhi oleh aktifitas yang berada disekitar.
\end{abstract}

Kata kunci: Pemantauan densistas debu, Sensor GP2Y1010AU0F, Uji statistik

\section{Abstract}

Air quality monitoring in electronic warehouses is essential to maintain human health and the quality of electronic goods. This study aims to monitor the value of dust density in a room, especially in electronic warehouses, and determine the relationship between dust density, temperature, and humidity. The method used in this research is the experimental and statistical test. The result from the statistical test shows that there is no relationship between dust density and temperature. This result is evidenced by the calculated chi-square value $(0.265)$, smaller than the chi-square table (1.645). Furthermore, there is no relationship between dust density and humidity, with the calculated chi-square value (0.1023) smaller than the chi-square table (1.645). The level of dust in the Electronic Warehouse of Depo Pelita from July 22 to July 30, 2021, has an average of $0.13 \mathrm{mg} / \mathrm{m3}$ or $130 \mathrm{~g} / \mathrm{m} 3$. The research results are that dust cannot be affected by temperature and humidity but is influenced by activities around it.

Key words: Dust density monitoring, Sensor GP2Y1010AU0F, Statistical test 


\section{Pendahuluan}

Kualitas udara dalam gudang elektronik yang baik sangat penting bagi kesehatan manusia dan kualitas barang elektronik. Mengingat banyaknya industri berskala besar diwilayah indonesia, yang memiliki suatu kebijakan untuk melakukan sistem persediaan (inventory) [1]. Pemantauan suatu indeks kualitas udara pada suatu ruangan yang diukur selama 24 jam menjadi salah satu tindakan untuk evaluasi kesehatan lingkungan, dimana hasil evaluasi tersebut akan digunakan untuk mengambil beberapa kebijakan yang berkaitan dengan pemeliharaan dan pengembangan kesehatan pada lingkungan [2].

Debu atau partikel kecil lainnya yang terdapat diudara dapat mengakibtkan berbagai kerusakan. Debu merupakan salah satu musuh terbesar pada barang elektronik, dimana debu yang menempel pada permukaan elektronik dapat menghalangi perputaran udara yang menyebabkan barang elektronik cepat rusak [3].

Debu merupakan polusi udara dengan diameter $\leq 500 \mu \mathrm{m}$, dimana salah satu contoh debu yaitu PM-2,5 dan PM-10 yang merupakan bahan partikulat yang memiliki diameter lebih kecil dari 2,5 $\mu \mathrm{m}$ dan $10 \mu \mathrm{m}$ yang diyakini memiliki resiko kesehatan yang cukup besar. Salah satu dampak yang dsebabkan oleh partikel ini ialah ISPA (Infeksi Saluran Pernafasan) dan juga dapat menyerang orang yang memiliki riwayat penyakit lainnya dan bahkan dapat menyebabkan kematian [4].

Sistem pemantau densitas debu gudang elektronik dalam penelitian ini dirancang dengan menggunakan microcontroller Nodemcu yang sudah dilengkapi dengan module Wi-Fi ESP8266 sehingga mempermudah para penggunanya. Muliawati merancang sebuah sistem otomatis pengukuran densitas debu dengan menggunakan microcontroller AT Mega dimana ukuran pada microcontroller ini lebih besar dibandingkan dengan Nodemcu dan belum dilengkapi dengan Wi-fi module [5]. Data yang diperoleh dalam penelitian ini akan diolah menggunakan pertitungan chi-square, yang merupakan salah satu jenis uji komparatif non parametris yang dilakukan pada dua variabel guna mengetahui hubungan antara densitas debu, suhu, dan kelembaban. Igo Cahya telah melakukan penelitian dengan menggunakan uji chi-square untuk mengetahui hubungan antara tingkat pendidikan dan umur terhadap pengetahuan HIV-AIDS [6].

\section{METODE}

Metode penelitian yang digunakan adalah studi literature, eksperimen, dan uji statistik dimana pada perhitungan uji statistik penulis menggunakan perhitungan chi-square yang merupakan salah satu jenis uji komparatif non parametris yang dilakukan pada dua buah variable, dimana skala pada kedua variabel adalah nominal. Prosedur dalam penelitian ini ada 3 tahap yaitu : 1) tahap perancangan, alat 2) tahap pengujian,alat 3) tahap hasil dan pembahasan.

\section{A. Tahap Perancangan Alat}

Tahap perancangan diawali dengan merancang sensor debu GP2Y1010AU0F, modifikasi website Antares yang digunakan untuk menampilkan hasil dalam bentuk grafik, dan beberapa perangkat keras pendukung untuk mengukur konsentrasi PM-2,5 dan PM-10 pada gudang elektronik. Perangkat keras pendukung yang digunakan diantaranya sensor temperatur dan kelembaban (DHT-11). Nodemcu bekerja sebagai mikrokontroller utama yang digunakan untuk mengatur jalannya sensor GP2Y1010AU0F dan sensor DHT-11. Data akan dikirimkan pada web Antares menggunakan WiFi yang tersedia. 


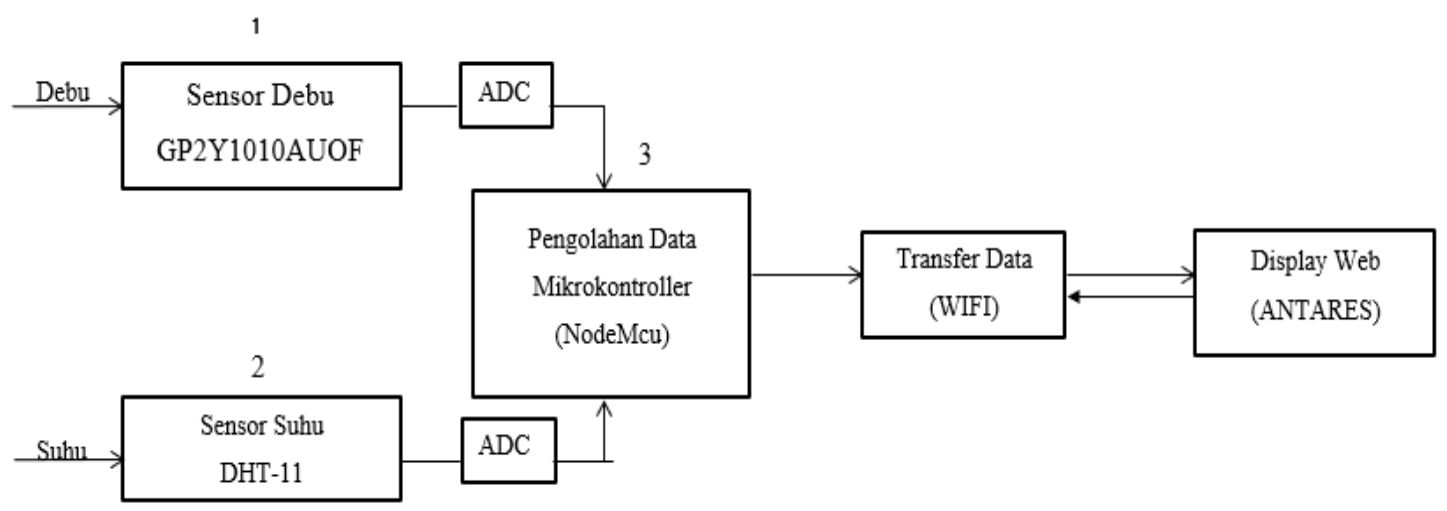

Gambar 1.a. Skema Rangkaian Sistem Monitoring Densitas Debu

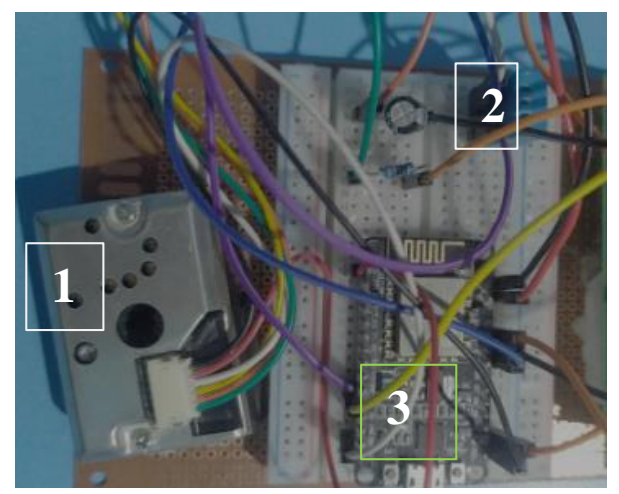

Gambar 1.b Foto Rangkaian Sistem Monitoring Densitas Debu

Pada blok diagram diatas menunjukan kinerja alat untuk memantau densitas debu gudang elektronik dimana sumber yang digunakan listrik arus DC, yang dapat diperoleh dari komputer. Nodemcu bekerja sebagai mikrokontroller utama yang mengatur jalannya sensor GP2Y1010AU0F dan juga sensor DHT-11. Data akan dikirimkan pada web Antares menggunakan WiFi yang tersedia

\section{B. Tahap Pengujian Alat}

Pengujian sistem dilakukan untuk menguji kestabilan dan sensitifitas perangkat. Dalam pengujian sistem penulis menggunakan skenario dimana sistem akan diletakkan pada meja dan kemudian diberikan residu atau debu. Residu yang digunakan dalam pengujian alat yaitu menggunakan, residu bedak bayi dengan ukuran 10mg.

\section{Hasil dan Pembahasan}

Berikut merupakan hasil dari pengujian alat yang dilakukan dengan mengukur densitas debu pada Gudang elektronik secara kontinyu, yaitu dilakukan secara bertahap dari hari kehari, serta dilakukan pada pagi hari (08;00-11:30) dan siang hari (13:00-17:00) 


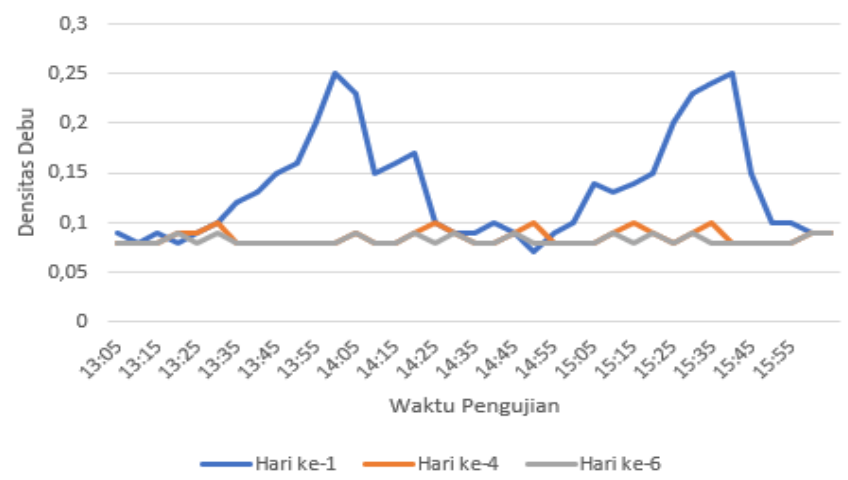

Gambar 2.a Densitas Debu Pada Pengujian ke-1 (13:00-17:00)

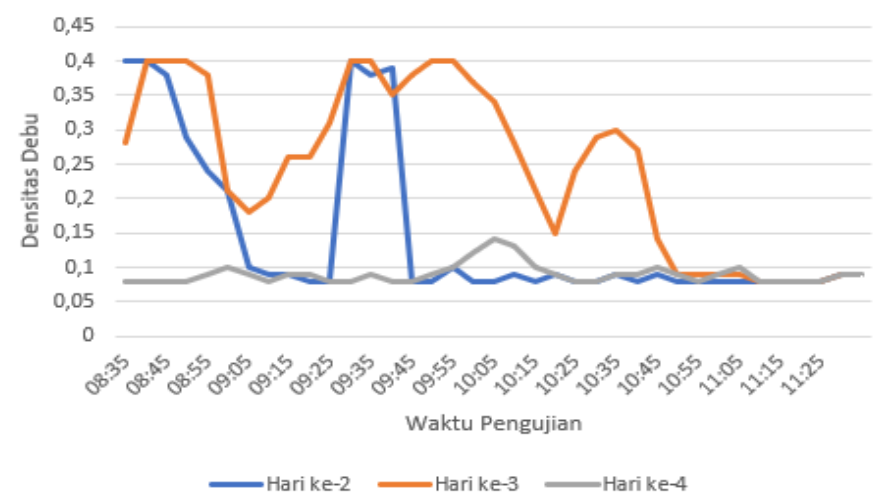

Gambar 2.b Densitas Debu Pada Pengujian ke-1 (08:00-11:30)

Suhu Pada Pengujian Siang Hari

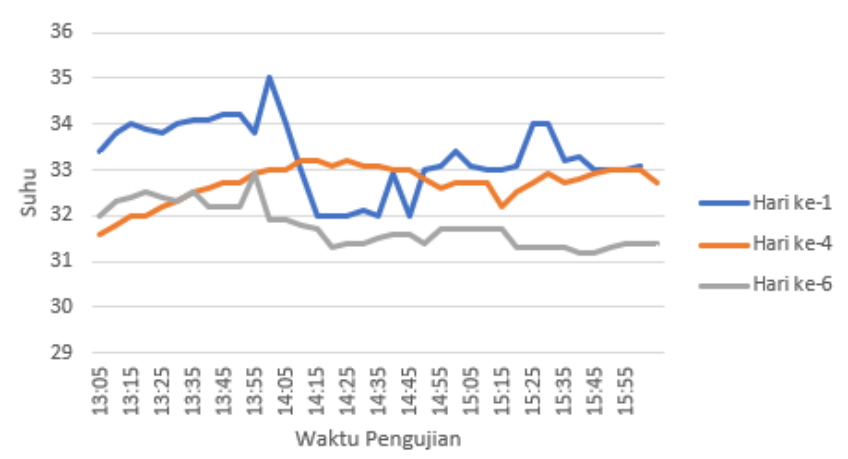

Gambar 3.a Nilai Suhu Pada Pengujian ke-2 (13:00-17:00)

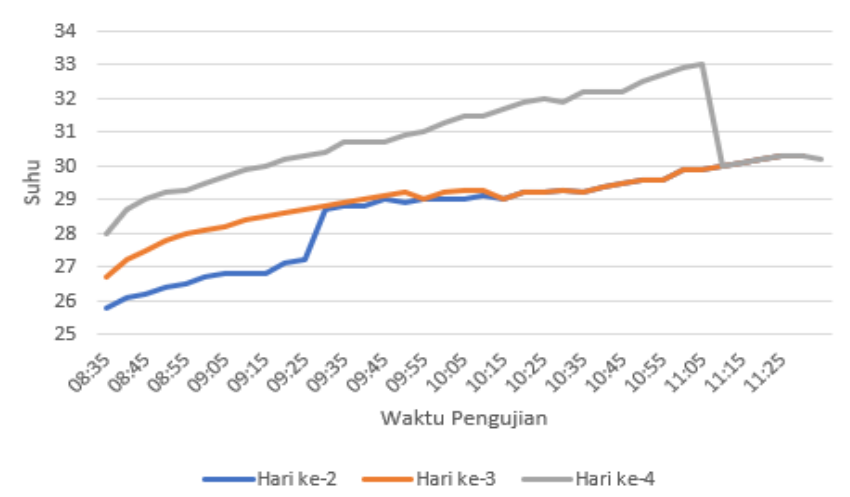

Gambar 3.b Nilai Suhu Pada Pengujian ke-2 (08:00-11:30) 


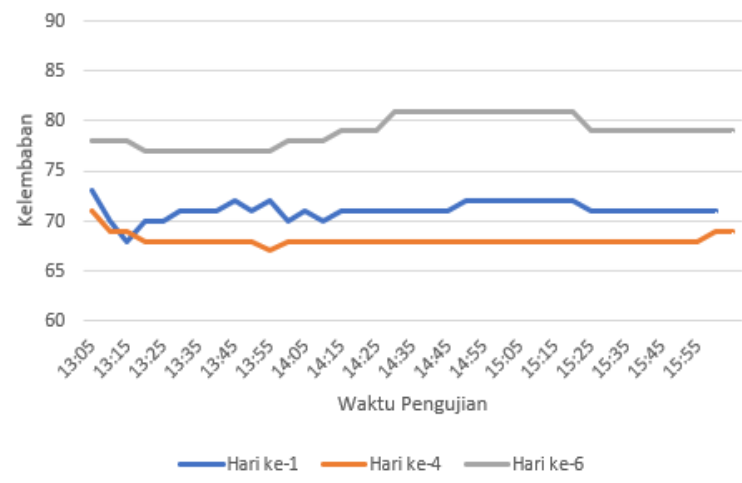

Gambar 4.a Nilai Kelembaban Pada Pengujian ke-3 (13:00-17:00)

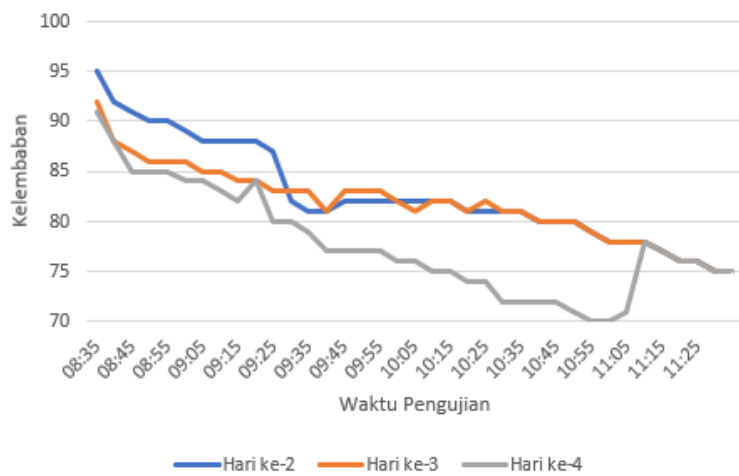

Gambar 4.b Nilai Kelembaban Pada Pengujian ke-3 (08:00-11:30)

Pada gambar ke 2.a dan 2.b terhadap 3.a dan 3.b diatas dapat dilihat bahwa tidak ada hubungan antara nilai densitas debu dan suhu, karena pada pengujian semakin tinggi nilai suhu, nilai densitas debu tetap stabil dikarenakan tidak ada aktifitas yang terjadi disekitar. dan kelembaban. Pada gambar 2.a dan 2.b terhadap 3.a dan 3.b diatas dapat dilihat bahwa tidak ada hubungan antara nilai densitas debu dan kelembaban, karena pada pengujian semakin tinggi nilai kelembaban, nilai densitas debu tetap stabil dikarenakan tidak ada aktifitas yang terjadi disekitar. Nilai debu dipengaruhi oleh aktifitas sekitar.

\section{A. Uji chi-square untuk hubungan densitas debu dan suhu}

Setelah melakukan perhitungan untuk mencari nilai chi-square hitung pada densitas debu dan suhu, diperoleh kesimpulan bahwa hasil chi-square hitung $(0,265)$ lebih kecil dibandingkan dengan nilai chisquare tabel dengan derajat kebebasan $\mathrm{df}=(1,645)$, maka hipotesa nol diterima, atau tidak terdapat hubungan antara debu dan suhu. Detail perhitungan chi-square dapat dilihat pada halaman informasi tambahan.

\section{B. Uji chi-square untuk hubungan densitas debu dan kelembaban}

Setelah melakukan perhitungan untuk mencari nilai chi-aquare hitung pada densitas debu dan kelembaban, diperoleh kesimpulan bahwa hasil chi-square hitung $(0,1023)$ lebih kecil dibandingkan dengan nilai chi-square tabel dengan derajat kebebasan $\mathrm{df}=1,645$. maka hipotesa nol diterima, atau tidak terdapat hubungan antara densitas debu dan kelembaban. Detail perhitungan chi-square dapat dilihat pada halaman informasi tambahan. 


\section{KESIMPULAN DAN SARAN}

Sistem monitoring densitas debu telah berhasil dibuat dan di coba selama 24 jam di salah satu gudang elektronik Depo Pelita Sokaraja. Berdasarkan hasil pengukuran dapat disimpulkan bahwa suhu dan kelembaban berkorelasi negatif dengan densitas debu, berdasarkan perhitungan uji statistik maka dapat disimpulkan bahwa tidak ada hubungan antara densitas debu dan suhu hal ini dibuktikan dengan hasil chisquare hitung $(0,265)$ lebih kecil dari chi-square tabel $(1,645)$ yang menyebabkan Ho diterima, maka tidak ada hubungan diantara debu dan suhu. Dan hasil pada uji statistik densitas debu dan kelembaban menghasilkan nilai chi-square hitung $(0,1023)$ lebih kecil dibandingkan dengan nilai chi-square tabel dengan derajat kebebasan $\mathrm{df}=1,645$. maka hipotesa nol diterima, atau tidak terdapat hubungan antara densitas debu dan kelembaban. Tingkat debu pada Gudang Elektronik Depo Pelita pada tanggal 22 juli 2021 sampai dengan 30 Juli 2021 memiliki rata-rata $0,13 \mathrm{mg} / \mathrm{m} 3$ atau $130 \mu \mathrm{g} / \mathrm{m} 3$.

Dengan melihat kekurangan dan juga keterbatasan dalam system ini maka untuk penelitian selanjutnya sebaiknya lebih mengembangkan beberapa perangkat keras yang digunakan, dan sebaiknya untuk melakukan uji coba ditempat yang berbeda.

\section{KONTEN TERKAIT}

Lampiran

Lampiran untuk artikel ini dapat diunduh melalui: http://journal.ittelkompwt.ac.id/public/journals/1/v3n2/4_AK_Lampiran_2.pdf. Lampiran berisi: Hasil Pengukuran Densitas Debu, Suhu, dan Kelembaban; dan Analisis Uji Statistik Chi-Square.

\section{Kontribusi Penulis}

AKP merancang sistem pemantau debu, melakukan pengujian, mengambil dan menganalisa data, serta menulis manuskrip jurnal. MAA melakukan review data dan analisanya. AP menyusun desain penelitian, mengevaluasi penelitian, serta mereview manuskrip.

\section{DAfTAR Pustaka}

[1] Muchlisin Riadi, "Pengertian, Tujuan dan Manfaat Gudang," 2016. https://www.kajianpustaka.com/2016/04/pengertian-tujuandan-manfaat-gudang.html (accessed Apr. 30, 2020).

[2] B. A. Februar, "Dengan Kapasitas Paru Tenaga Kerja Kabupaten Banyumas Tahun 2015," Keslingmas, vol. 35, pp. 103-106, 2016.

[3] R. Ratnani, "Teknik Pengendalian Pencemaran Udara Yang Diakibatkan Oleh Partikel,” J. Momentum UNWAHAS, vol. 4, no. 2, p. 114195, 2008.

[4] R. Purbakawaca et al., "Rancang Bangun Alat Ukur Pm10 Rendah Biaya Menggunakan Sensor Debu Gp2Y1010Au0F," J. Online Phys., vol. 3, no. 1, pp. 6-13, 2018, doi: 10.22437/jop.v3i1.4390.

[5] F. Muliawati and A. Seftiana, "Debu, Kelembaban Udara, Dan Suhu Ruang Berbasis Untuk Sterilisasi Udara Pada Ruang Perakitan Lensa Kamera," pp. 18-25.

[6] J. Matematika et al., "PENGGUNAAN UJI CHI - SQUARE UNTUK MENGETAHUI PENGARUH TINGKAT PENDIDIKAN DAN UMUR TERHADAP PENGETAHUAN PENASUN MENGENAI HIV - AIDS DI PROVINSI DKI JAKARTA Igo Cahya Negara Agung Prabowo Jurusan Matematika , FMIPA Universitas Jenderal Soedirman , Purwokert,” 2018. 